\title{
The light color quality of LEDs operating at winter temperatures
}

\author{
Przemyslaw Tabaka, ${ }^{*}$ and Pawel Rozga
}

\begin{abstract}
Lodz University of Technology, Institute of Electrical Power Engineering, Stefanowskiego 18/22, 90-924 Lodz
\end{abstract}
Received November 30, 2019; accepted December 13, 2019; published December 31, 2019

\begin{abstract}
The paper presents the results of calculations of colorimetric parameters of LED sources operating at a temperature range from $-25^{\circ} \mathrm{C}$ to $25^{\circ} \mathrm{C}$. The chromaticity coordinates and color rendition quality parameters were calculated based on registered spectral distributions of radiation. For individual LEDs, chromaticity shift is illustrated at CIE 1931 x, y diagram with 3 step and 7 step MacAdam ellipses.
\end{abstract}

Until recently, low-pressure fluorescent lamps (FL lamps) were one of the most popular light sources used both in interior lighting installations and in outdoor lighting [1-3]. The fluorescent lamps in outdoor lighting are used to illuminate underground passages, parking lots, public transport stops, bus and railway platforms or signs, billboards and advertising panels [4]. The fundamental disadvantage of these types of lamps, as noted in the literature [5], is the fact that with decreasing the ambient temperature (operating temperature of a lamp), the luminous flux also decreases, which adversely affects luminous efficiency (the parameter being a measure of energy saving) [6]. Additionally, in such a case the color parameters of the emitted light change as well [7].

Due to the European Union regulations it has become a necessity to save the electricity [8]. For this reason, in many applications, fluorescent lamps are replaced by LED sources, which luminous efficiency improves as the ambient temperature decreases [9]. The manufacturers of light sources provide photometric and colorimetric parameters for an ambient temperature equal to $25^{\circ} \mathrm{C}$ [10, 11]. However, when LED sources are used in outdoor lighting, the operating conditions differ from those corresponding with this temperature.

One of the most important issues related to the design of LED sources is the impact of the ambient temperature on the color properties of radiation emitted by these light sources, because the change of the color of a white light in lighting installations can be troublesome.

To describe the change in color parameters of the light sources, it is necessary to have access to the measurement data in this field. In relation to the 14 LED sources, operating in the range of temperature changes from $+25^{\circ} \mathrm{C}$ to $-25^{\circ} \mathrm{C}$, the Spectral Power Distributions (SPDs) were measured with a $5^{\circ} \mathrm{C}$ step [12-13]. Due to a large number of measurement data, Fig. 1 shows the examples of SPDs

*E-mail: przemyslaw.tabaka@p.lodz.pl for two LED sources selected. Individual data presented in Fig. 1 were normalized to SPD for an ambient temperature equal to $25^{\circ} \mathrm{C}$.
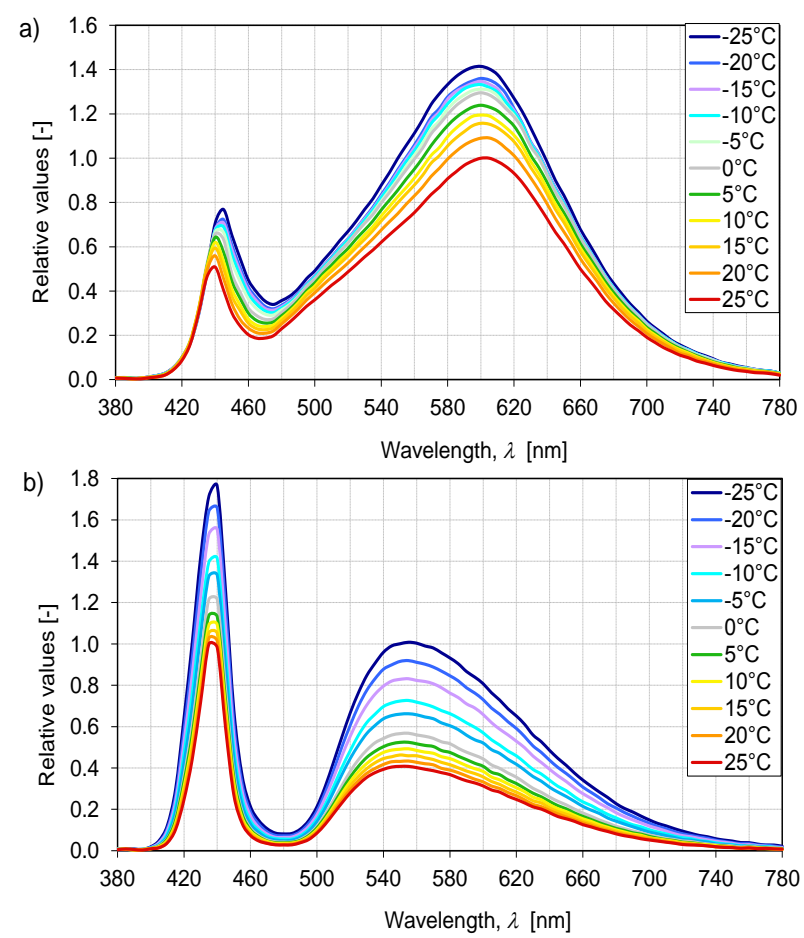

Fig. 1. The SPDs of LED: a) warm white, b) cool daylight.

For a given LED, chromaticity coordinates were calculated based on its measured SPDs, and were graphically presented on the CIE 1931 x,y chromaticity diagram (Fig. 2) . The coordinates were determined for 14 LEDs operating at an ambient temperature of $25^{\circ} \mathrm{C}$. Figure 2 additionally contains the Planckian locus (black body locus) and iso-CCT lines [14].

The consequence of the SPD change (Fig. 1) along with the ambient temperature will be a change in light color which corresponds to the chromaticity shift (change in the position of the chromaticity point on CIE $1931 \mathrm{x}, \mathrm{y}$ chromaticity diagram). This effect was illustrated for individual LED sources in Figs. $3 \div 7$. In order to observe the trend in the color changes, additionally the MacAdam ellipses were presented in Figs. $3 \div 7$. At the central point 
of the ellipse is the chromaticity point for light emitted by a LED working at an ambient temperature of $25^{\circ} \mathrm{C}$.

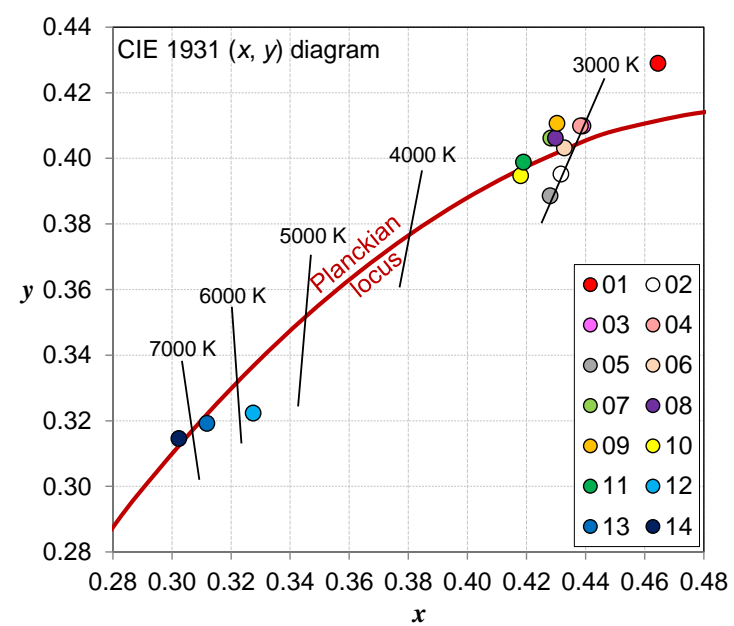

Fig. 2. The light sources chromaticity point $(x, y)$ value.

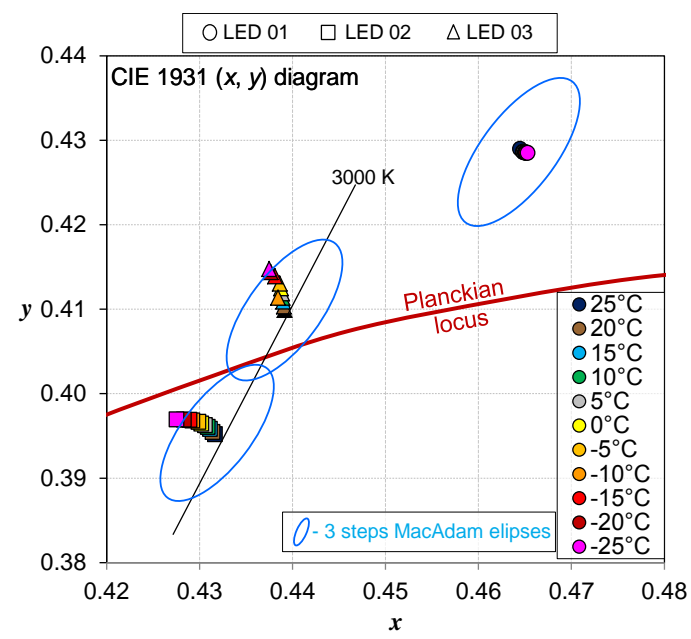

Fig. 3. The light sources chromaticity point $(x, y)$ value for LED 01 , LED 02 and LED 03 sources.

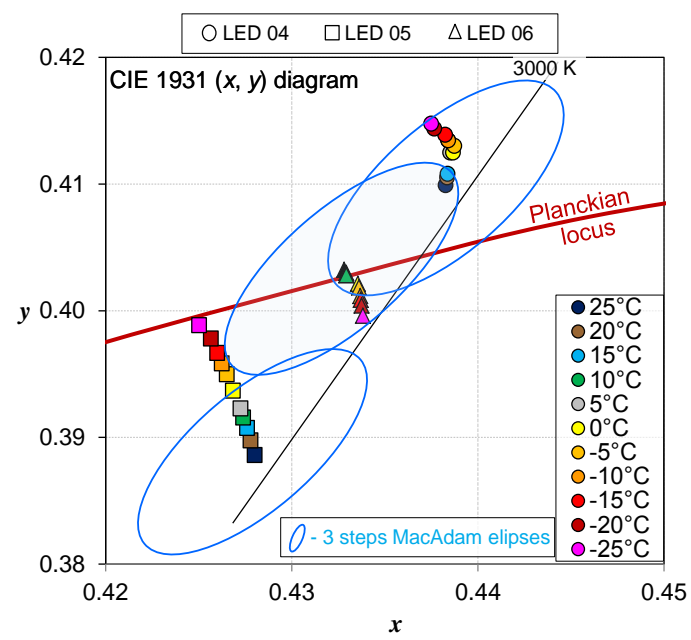

Fig. 4. The light sources chromaticity point $(x, y)$ value for LED 04 , LED 06 and LED 06 sources.

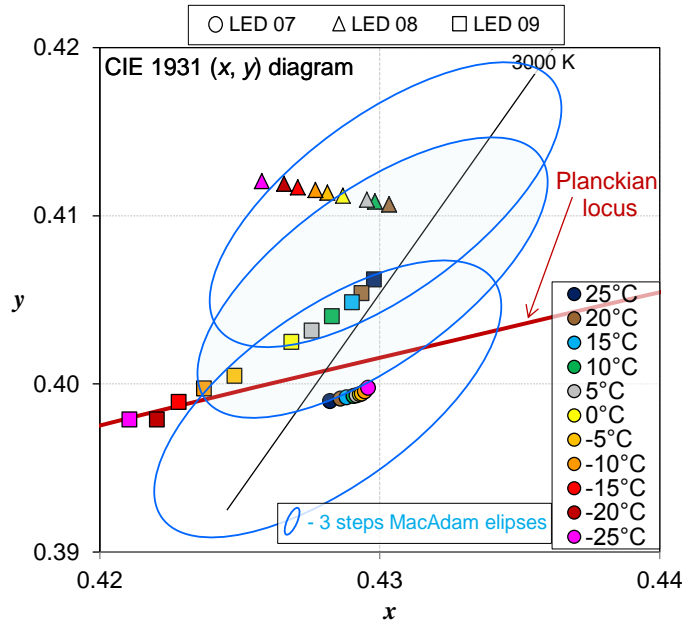

Fig. 5. The light sources chromaticity point $(x, y)$ value for LED 07 , LED 08 and LED 09 sources.

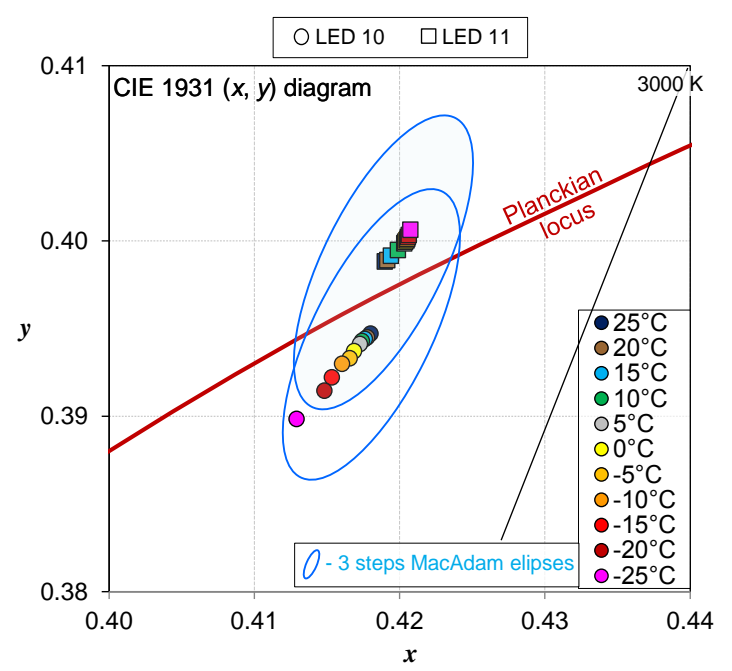

Fig. 6 . The light sources chromaticity point $(x, y)$ value for LED 10 , and LED 11 sources.

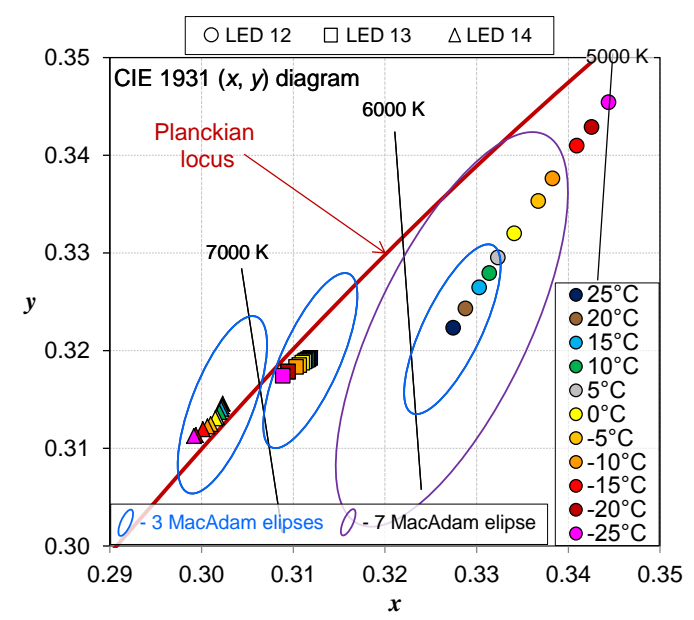

Fig. 7. The light sources chromaticity point $(x, y)$ value for LED 12 , LED 13 and LED 14 sources. 
Among the 14 LED sources, for most of them the reduction of the ambient temperature below $25^{\circ} \mathrm{C}$ will not cause a significant change in the color of light. Chromaticity points for most of the LED sources tested (LED 01; LED 05; LED 06; LED 07; LED 10; LED 11; LED 12 and LED 13) are inside the MacAdam 3 steps ellipse. However, for 3 LED sources (LED 02; LED 03 and LED 08) only at $25^{\circ} \mathrm{C}$ the chromatic coordinates slightly exceed the area of the MacAdam 3 steps ellipse.

Larger changes in light color were noted for lamps LED 05, LED 09 and LED 14. In the case of LED 14 chromatic coordinates exceed the area of the MacAdam 7 steps ellipse. It is clearly visible that the color of emitted light in this case becomes warmer with a decrease of the ambient temperature.

The chromaticity point, despite clearly defining the color of emitted light, does not provide information about the appearance of the color of the illuminated objects. Such a parameter is CRI (Color Rendering Index) [15-16], which is a measure of color rendering of the light emitted by a given lamp and also the color fidelity index $R_{f}$ which has been introduced by the International Commission on Illumination (CIE) in 2017 [17]. The issue of the quality of light color rendition is a very broad issue, which is confirmed by many papers published in this field [18-26].

For all LED sources tested CRI and $\mathrm{R}_{\mathrm{f}}$ values were determined when LED sources operate at specific ambient temperatures. Since the changes in the mentioned indicators are insignificant, they have not been presented graphically. In the case of LED 14, for which the color changes are greatest, both the changes of CRI and $R_{f}$ do not differ by more than 2 units. Such a small difference cannot be recognized or noticed by any observer (the difference with 5 units could be recognized by welltrained observer)

On the basis of the studies conducted, it can be concluded that replacing (in outdoor lighting) FL lamps by LED sources is a good solution because LEDs in contrast to FL lamps do not change their light color quality with a decrease of the ambient temperature - for example in cold winter.

\section{References}

[1] J.P. Freyssinier, D. Frering, J. Taylor, N. Narendran, P. Rizzo, Proc. SPIE 6337, 63371L (2006)

[2] M.M. Aman et al., Analysis of the performance of domestic lighting lamps (Energy Policy, 2013). http://dx.doi.org/10.1016/i.enpol.2012.09.068

[3] E. Elijošiute, J. Balciukevičiute, G. Denafas, Environ Res. Eng. Manag. 61(3), 65 (2012). http://dx.doi.org/10.5755/j01.erem.61.3.2425.

[4] D. Czyzewski, Przeglad Elektrotechniczny R. 88, 11 (2012).

[5] P. Tabaka, P. Rozga, Bulletin of the Polish Academy of Sciences Technical Sciences 65, 6 (2017). doi: 10.1515/bpasts-2017-0095

[6] I. Fryc, P. Jakubowski, K. Kołacz, Przeglad Elektrotechniczny R. 93(11), 186 (2017). doi: 10.15199/48.2017.11.38

[7] T. Kawabata, Y. Ohno, J. Modern Opt. 60(14), 1176 (2013).

[8] W. Żagan, Przeglad Elektrotechniczny R. 85(5),10 (2009).
[9] P. Tabaka, Light \& Engineering 23(2), 70 (2015).

[10] W.R. Ryckaert et al., Energy Build. 49, 429 (2012) http://dx.doi.org/10.1016/J.ENBUILD

[11] M. Zalesinska, J. Zablocka, K. Wandachowicz, Evaluation of Selected Parameters of Non-Directional Household Lamps, Conference: 2018 VII. Lighting Conference of the Visegrad Countries (Lumen V4); doi: 10.1109/LUMENV.2018.8521102

[12] I. Fryc, Przeglad Elektrotechniczny R. 85(11), 317 (2009).

[13] IESNA, IES Approved Method: Measuring Lumen Maintenance of LED Light Sources. IES LM-80-08', IES Subcommittee on Solid-State Lighting of the IES Testing Procedures Committee (2018).

[14] D.B. Judd, J. Opt. Soc. America 26(11), 421 (1936). http://dx.doi.org/10.1364/JOSA.26.000421

[15] CIE 177:2007 Colour Rendering of White LED Light Sources.

[16] CIE 13.3-1995 Method of Measuring and Specifying Colour.

[17] CIE 224:2017 Colour Fidelity Index for accurate scientific use.

[18] CIE 15:2004 Colorimetry.

[19] D. Mozysrska, M. Wyrwas, I. Fryc, Przeglad Elektrotechniczny R. 93(4a), 232 (2012).

[20] J. Kowalska, Przeglad Elektrotechniczny R. 93(6), 50 (2017). doi: $10.15199 / 48.2017 .06 .13$

[21] J. Kowalska, I. Fryc, Przeglad Elektrotechniczny R. 95(7), 94 (2019). doi:10.15199/48.2019.07.20

[22] J. Kowalska, Przeglad Elektrotechniczny R. 93(5), 74 (2017). doi: 10.15199/48.2017.05.14

[23] I. Fryc, J. Fryc, A. Wasowski, Przeglad Elektrotechniczny R. 92(2), 218 (2016). doi: 10.15199/48.2016.02.55

[24] I. Fryc, Przeglad Elektrotechniczny R. 86(10), 187 (2010).

[25] A. David, P. Fini, K. Houser et al., Opt. Expr. 23(12), 15888 (2015).

[26] K. Houser, M. Mossman, K. Smet et al., LEUKOS 12(1-2), 7 (2016). 